\title{
“Towards a Stylistic Account of Semantic/Pragmatic Deviation in Robert Browning's the Last Ride Together \& A Grammarian's funeral Poems"
}

Qasim Abbas Dhayef, English Department, College of Education for Human Sciences, Babylon University, Iraq, qasimabbas@uobabylon.edu.iq

Abdul-Haq Abdul-Kareem Al-Sahlani, English Department, College of Education for Human Sciences, Babylon University, Iraq, s.savu77@yahoo.com

\begin{abstract}
The present study stylistically investigates the semantic/pragmatic deviation in two poems by Robert Browning. It aims at pointing out and detecting the types of linguistic and extra-linguistic deviations Browning skillfully uses, which triggers out his stylistic excellence. The study, however, endeavors basically to investigate semantic and pragmatic deviations in 'The Last Ride Together' (1855) and 'A Grammarian's funeral' (1855). It shows how Browning deviates from the norms of language to achieve a deep insight of stylistic and aesthetic functions.

As for the hypotheses, it is hypothesized that Browning's poetry is uniquely deviant, his trend of writing is meant to achieve stylistic effects, and it is also hypothesized that most deviations in Browning's poetry occur on the linguistic (specifically, semantic) and extra-linguistic (particularly, pragmatic) levels of language.

Browning employs different types of deviation to achieve literary and aesthetic effects, which in many instances in his poems creates difficulty of understanding. Hence, Scott's (2015) WordSmith Tools, a software program, is adopted here so that the frequencies of occurrence for each type of deviation can be clearly seen as a stylistic marker or fingerprint of Browning's style.
\end{abstract}

Keywords: Poetic Language, Style, Stylistics, Deviation \& Word Smith Tools.

Received: 07.12.2020 $\quad$ Accepted: 22.01.2021 $\quad$ Published: 01.02.2021

\section{INTRODUCTION}

Opening an investigation of Browning's style, this study has addressed itself to stylistic deviation, especially semantic and pragmatic deviations. Such deviations are employed by Robert Browning so as to attract the addressees' attention to the unusualness of deviant expressions in two selected poems.

Finding out the nature of the relationship between poetic and ordinary languages, this paper explores the defining characteristics of both. Plus, identifying the salient differences and/or similarities between the two language varieties. Thus, it is expected to reveal whether or not the poet is bound by the norms of the standard language.

However, Robert Browning (1812-1889) is typically a representative of such poets. He has his own style of writing poetry and shows special peculiarities in handling language which characterize his own style. Therefore, the researcher selected two of Browning's poems to form the data of the study.

Handling the problem of this study, it is concerned with how the use of deviation as a literary device renders the language of poetry strange, odd, complex, obscure and linguistically incoherent. Since Browning employs different types of deviation to achieve the literary effects intended, he violates the norms of language, which in many instances of his poems creates difficulty of understanding. Hence, the problem the researcher aims to tackle might be formed in terms of the following research questions:

1. How does the use of deviation render strangeness or obscurity in poetic language?

2. Does Browning's use of deviation create a difficulty of understanding the poetic language? 


\section{LITERATURE REVIEW}

\section{Poetic Language vs. Ordinary Language}

Poetic language, as it is commonly thought, is beyond ordinary language. It is something that is essentially different, special, more elevated, more eloquent with extraordinary tools and techniques, skilful use of schemes and tropes (i.e., the use of instruments beyond the reach of ordinary language). As regards the relationship between poetic language and ordinary language, and whether or not the poetic language is a variety of the ordinary language, Stakiewicz (1960: 70) maintains that causal (ordinary) language is being subject to systematic description, whereas poetic language deviates from the linguistic norm :

However, poetic language need not violate any rules of language and still remains what it is, that is a highly patterned and organized language takes full cognizance of the rules of the linguistic system, and, if it admits deviations, they themselves are conditioned by the language or by the given poetic tradition.

Leech (1969: 5), similarly, differentiates between the language of poetry and any other type of linguistic activity in terms of deviation from the norm; asserting that "Poetic language may violate or deviate from the generally observed rules of the language in many different ways, some obvious, some subtle" (ibid). Accordingly, there is "no single property that characterizes poetic language permanently and generally. Poetic language is permanently characterized only by its function; however, function is not a property but a mode of utilizing the properties of a given phenomenon" (Mukarovsky, cited in Herman, 1995: 160).

Therefore, Jones (2012: Para 3) asserts that poetic language has an aesthetic function concentrated on attention and on the linguistic sign itself. It makes people think about how language works in a rather a specific mode of communication (ibid).

Accordingly, drawing a clear-cut borderline of demarcation between ordinary language and poetic language, involves the study of the features and characteristics of each, to reach a convincing boundary where they may meet or depart. Yet, at this point, it may be possible to infer that poetic language cannot be studied apart from ordinary language, i.e., poetic language deviates from the general rules of (ordinary) language (Hutton, 2018: 77-80).

\section{Style \& Stylistics}

Style has been an object of interest in ancient times for 'grammar' and 'rhetoric', and in modern times for 'literary studies', 'linguistics', and 'stylistics'. Yet, it seems that there is no definition of style unanimously agreed upon. Instead, one finds a whole range of propositions, definitions and an even wider range of terms linguists, critics and stylisticians use to describe any particular style.

Crystal and Davy (1969: 9-11) assert that the term ' style' has multiple definitions because it is a very familiar word to most people. They list four senses of the term 'style' which they consider to come within the purview of stylistics:

1. Style may refer to some or all of the language habits of one person- as when one talks of Browning's style (or styles), or the style of any other creative writer- or when one discusses questions of disputed authorship.

2. In a similar way, style may refer to some of all the language habits shared by a group of people at one time, or over a period of time- as when one talks about the style of the Victorian poets.

3. Style is given a more restricted meaning when it is used in an evaluative sense, referring to the effectiveness of a mode of expression. This is implied by such popular definitions of style as ' saying the right thing in the most effective way' or as ' good manners'. When one talks of a 'clear' or ' refined' style then one is making value judgments on the overall effect of the language on oneself.

4. Partly overlapping with the three senses just outlined is the widespread use of the word ' style' to refer solely to literary language, because style has long been associated with literature as a characteristic of 'good', 'effective', or 'beautiful' writing.

The current study is going to adopt the first approach, since the concern of the study is to study the stylistic impact of deviation on the poetry of Browning.

The notion of 'style as deviation', that is the transgression of a norm, has developed recently into a modified form. One no longer speaks of the language of a writer as deviation from a norm but from the whole of poetic language (Leech \& Short, 1981: 30).

The term 'style' has acquired many definitions and various interpretations by different scholars, which adds to the complexity of selecting a particular and a more comprehensive definition. For instance, 
Jurus (1994: 4) defines style as "the way in which language is used in a given text, determined by the frequency of occurrence of particular linguistic features in that text ". As for Askeberg, (2004:2), he highlights the importance of the effect endowed to words in any particular style. He states that style is "the way in which, in a particular situation, you succeed to give your words an intended effect" (ibid).

Giving different varieties and perspectives of what style is, it is time to have a look at what the areas of interest of stylistics are. In fact, Hussein \& Al-Sahlani (2019: 45) have summed up those areas:

[A]ny researcher tries to reach at [those areas] including: the investigation of the linguistic features, the style of the authors and their texts as well as the language itself. Through these areas, stylistics proves itself to be a powerful, useful and significant approach to study texts, discourses and even the ways people use their own languages. "style is involved with a deviation from a norm, or the standard use of the language, to reach at literary, persuasive, rhetorical or other effects (ibid).

Generally speaking, stylistics applies linguistics to literature in the hope of arriving at analyses which are more broadly based, rigorous and objective. The pioneers were the Prague and Russian schools, but their approaches have been appropriated and extended by radical theory in recent years. Tackling the major aim of stylistics, it goes hand in hand with language (written or spoken) to identify stylistically significant features of that language, or style markers, and the functions they fulfill (Crystal \& Davy, 1969).

Altogether, stylistics in its most general usage is "The study of any situationally distinctive use of language, and of the choices made by individuals and social groups in their use of language" Crystal (1992: 371).

Munday \& Chandler (2020, para: 1) declare that stylistics is a mode of analyzing literature that focuses on aspects of form rather than aspects of content and that may be used to determine the distinctive features of a literary work, an author, or a particular literary period.

Proving that stylistics indeed holds a firm position within linguistics, this idea is supported by Jeffries \& McIntyre (2010: 3) when they say:

Stylistics has a firm place within linguistics, providing theories of language and interpretation which complement context-free theories generated within other areas of language study (ibid).

Consequently, stylistics, in fact, pays much attention to casual and formal styles of speech utilized by speakers, often reflecting different degrees of attention to speech. This is due to the changes occurred in topic, setting, and even audience (Hussein \& Al-Sahlani, 2019: 48). In this way the researcher can tell that "stylistics does really hold a firm position within the kingdom of linguistics. In fact, it is an advanced stage of practicing linguistics" (ibid).

\section{Style as Deviation \& its Types}

In order to fully understand the relation between the deviant structures of a text and the ordinary language, it is important to consider some types of deviation. Most linguists advocate to classify deviations into two major types: the first type is called 'internal deviation', it is that type which takes place against the background of the literary work where the norm is said to be the rest of the text. Leech \& Short (1981: 55) affirm that features of language within a text may depart from the norms of the text itself that is "they stand against the background of what the text has led us to expect", this is the phenomenon of 'internal deviation' which is most strikingly frequent in poetry. The second type is called 'external deviation' which is intended to appear against some norms outside the world of the literary work itself.

A further consequence of the presence of the two types in literary language is that they are supposed to take place in all linguistic levels: phonology, morphology, syntax, semantics and pragmatics (Rabah, 1997: 80).

A detailed account of deviation and its types is produced by Short (1996) highlighting the importance of deviation especially in the language of poetry. Thus, Short (ibid) proposes the types of deviation into: phonological, graphological, grammatical, morphological, lexical, semantic, discoursal and pragmatic deviations. What attracts the researcher's attention here, in this paper, is to detect only the semantic/pragmatic deviations. Other types of deviation will not be tackled in this regard.

\section{Semantic Deviation}

The discussion of semantic deviation in poetry shows that the salient feature to be considered is the irrational element that is present in almost all poetry. Leech (1969: 48) holds that semantic deviation is presented mostly through what is mentally termed 'nonsense' or 'absurdity'. He adds that it is commonplace to regard a 
poem as a kind of inspired nonsense. Wordsworth's the child is the father of the man represents 'nonsense' by all standards of poetic appreciation.

The superficial absurdity of Wordsworth's apophthegm forces the addressee to look beyond the literal meaning of words to arrive at a reasonable interpretation. One should understand 'father' in another sense than that of progenitor. Here, the figurative meaning becomes necessary because the literal meaning is absurd (ibid).

Semantic deviation, however, is defined as "meaning relations which are logically inconsistent or paradoxical in some way" (ibid), metaphors fit into this categorization (inconsistent semantic relations). It is occurred to heighten the effect of mental disarray which makes itself felt through the suppressing of logical semantic links, creating a disturbing atmosphere or a total failure to understand" (Hussein, 2014: 20-21). In poetry, there are different devices whereby semantic deviation might be arrived at, the most important ones are the following:

\section{Pleonasm}

Leech (1969: 132) defines pleonasm as " any expression which is semantically redundant in that it merely repeats the meaning contained elsewhere, in what precedes or follows it" (e.g.,: my female grandmother; a false lie; a philatelist who collects stamps).

Pleonasm is often understood to mean an excess word or phrase which is unnecessary, clichéd, or wrong. Yet a pleonasm can also be simply an unremarkable use of idiom. It can even aid in achieving a particular linguistic effect, whether it is social, poetic, or literary. In other words, pleonasm sometimes serves the same function as rhetorical repetition, i.e., it reinforces a point, and makes the writing clearer and easier to understand (ibid).

\section{Tautology}

Leech (ibid: 133-7) defines tautology as "A statement which is vacuous, because self- evidently true", (e.g., my grandmother is female; that lie is false; philatelists who collect stamps). Tautologies do not tell us something about the world, rather they tell something about the language, i.e., they are uninformative. Like pleonasm, tautology is a device of limited usefulness in literature.

\section{Periphrasis}

Crystal (2004: 344) defines periphrasis as "a term used in grammatical description to refer to the use of separate WORDS instead of INFLECTION to express the same grammatical relationships". He (ibid.) gives the example of the comparison of adjectives involving both inflections (e.g. happier, happiest) and periphrastic forms (more happy, most happy), although most adjectives use only one or the other of these possibilities.

\section{Paradox}

Leech (1969: 132) defines paradox as " a statement which is absurd, because self-evidently false... ", i.e., a paradox is an apparently true statement or group of statements that seem to lead to a contradiction or to a situation that defies intuition. An example of paradox in Browning's poetry is manifested at the conclusion of his poem 'A Grammarian's Funeral', where two totally contradictory items are joint in one statement living and dying:

Lofty designs must close in like effects:

Loftily lying,

Leave him _ still loftier that the world suspects, Living and dying. (mypoeticside.com)

\section{Metaphor}

Metaphor is a trope or figurative expression in which a word or expression is shifted from its normal usage to a context where it evokes new meanings. It invokes a transaction between words and things. The metaphor is the most significant feature of poetic style (Hartmann and Stork, 1981: 84). For example, the evening of one's life, food for thought and time is money not only change but extend one's understanding of such ideas. Browning enriches his poetry with beautiful metaphors that appeal both to the mind and the heart of the reader. In his poem 'Prospice', Browning compares implicitly, through metaphor, life to a journey and death to 'Arch Fear': 
Where he stands, the Arch Fear in a visible form

Yet the strong man must go:

For the journey is done and the summit attained,

And the barriers fall, (mypoeticside.com)

\section{Pragmatic Deviation}

As far as pragmatic deviation is concerned, Bowles (2010:29) believes that such a type can involve poetic deviation with written texts, "incongruities of storytelling behavior interpretable as violations of principles of cooperation and politeness, [it] mismatches between story and context and non-conformity with dramatic conventions" (ibid).

One of the great challenges of pragmatics is how to deal with the phenomenon of utterances with completely non-compositional meaning; those which are nothing like the sum of their parts. In many cases, one is confronted by an utterance which is composed of words one understands, but which, in context; have a completely unrelated meaning established in an apparently unprincipled way, (Cummins, 2002: 5).

Wardhaugh (2010: 308), following Grice (1975), defines the cooperative principle as " make your conversational contribution such as is required at the stage at which it occurs, by the accepted purpose or direction of the talk exchange in which you are engaged". He (ibid.) avers that the maxims and submaxims subsumed under this principle are as follows:

\section{Quantity}

1. Make your contribution as informative as is required (for the current purpose of the exchange).

2. Do not make your contribution more informative than is required.

A. Quality: try to make your contribution one that is true.

1. Do not say what you believe to be false.

2. Do not say that for which you lack adequate evidence.

B. Relation: be relevant.

C. Manner: be perspicuous:

1. Avoid obscurity of expression.

2. Avoid ambiguity.

3. Be brief (avoid unnecessary prolixity).

4. Be orderly.

Van Dijk (1977: 46-54) states that all Gricean Maxims are violated in literary communication, and that the addresser 'opts out' from the contextual principles of ordinary conversation and that the 'Cooperative Principle' does not hold. He proposes the cooperative principle from which the four literary counterparts of the Gricean principle are derived. Accordingly, the researcher infers that the breaking of any of the maxims of the cooperative principle does not mean that there is a total breakdown of communication, (i.e., there might be a partial violation of one of the maxims or the cooperative principles). The breaking of a maxim may also involve some kind of 'trade-off', where one breaks a maxim in order to maintain another maxim, the latter of which may be more important in the communicative situation than the former.

\section{METHODOLOGY}

In order to accomplish the entire study that the researcher starts, both qualitative and quantitative analyses will be held in the coming pages on identifying the main types of stylistic deviation: linguistic deviation ( especially semantic) and extra-linguistic (especially pragmatic). Thus, a detailed account of each type of stylistic deviation is accompanied by illustrative examples from Browning's poems. Hence, Scott's (2015) 'WordSmith Tools', a software program, is quantitatively adopted here so that the frequencies of occurrence for each type of deviation can be clearly seen as a stylistic marker or fingerprint of Browning's style.

The researcher, however, is going to investigate the use of stylistics deviation in two poems of Browning, and, also study its importance, its effect on the overall message, the intended meaning and the lucidity and comprehension of the poems. The analysis of the selected poems shall delineate the effect of semantic and pragmatic deviations on the style of Browning in the poems under discussion. The purpose of this part is to analyze the poems insofar as deviations are concerned, i.e., semantic and pragmatic deviations. Plus, it clarifies the topic of stylistic effect of deviations on the style of Browning. 


\section{Data Collection and Reliability of Data Source}

Data reliability is accomplished through authentic investigation. The researcher gained Robert Browning's The Last Ride Together and A Grammarian's funeral Poems from the most authentic and reliable websites (i.e., www.mypoeticside.com \& www.gradesaver.com). Each poem is transformed from Portable Document Format (PDF) into Plain Text Format (TXT) so that the user-friendly program (WordSmith Tools) can do its job precisely.

\section{Data Graphs}

The statistical analysis ( i.e., the output) resulted from WordSmith Tools will be graphitized in terms of tables. However, an excel spreadsheet (i.e., Microsoft Office Excel) is further used so that the researcher can design visual curves to detect the frequencies of occurrence for each type of deviation. This, in turn, can be clearly seen as a stylistic marker or fingerprint of Browning's style.

\section{Data Processing through the Use of Word Smith Tools}

Reaching the core analysis of this study, WordSmith Tools (henceforth WS) will analyze and compute the frequencies of occurrence for each type of deviation (i.e., semantic and pragmatic deviations). Knowing the essence of WS Tools, such tools operate on three major functions (e.g., Concordances, Wordlists and Keywords), (Zhang, 2014: 53). Hence, it is "developed by Mike Scott in 1996, predominantly for use by teachers and students in linguistics" (Easterby-Smith et al., 2012: 191).

\section{DATA ANALYSIS \& RESULTS}

\section{Analysis of Semantic Deviation in Poem No. (1)}

This poem does not involve much emphasis on semantic deviation, yet it is not empty of the usual semantic deviations encountered in the poetry of Browning. Semantically speaking, the poem is reasonable and the lines flow lucidly without many illogical sentences.

To begin with, in (line 6) the word whole is periphrastic, when one says for example my whole heart the word whole does not add any thing to the meaning, in addition we cannot take the 'heart' into parts so there is a whole and parts.

In (line 23) the poet metaphorically compares his beloved to a western cloud. He imaginatively adds more meaning to the metaphor through comparing the way his beloved laid her head on his breast with the falling of a cloud. The comparison of a lady with a cloud is semantically deviant.

In (line 24) he also uses another metaphor describing the cloud as having a breast billowy-bosomed. He gives animate characteristic to an inanimate entity.

Browning uses an implicit comparison when, he, in (line 31) says heaven was here, heaven here refers to his beloved, i.e., semantic deviation is achieved because the poet compares his beloved to heaven which is normally semantically deviant.

In (line 32) an instance of semantic deviation is detected through combining two extremely opposite terms together, i.e., the description of the inner state of the addresser as being both in joy and fear. This statement is apparently defying intuition, it is absurd. Yet, if one takes the two words from another perspective, a logical interpretation of the sentence may arise. The addresser's joy is certainly heavenly, he is having his beloved's head on his shoulder, but his joy was mingled with the fear that she might withdraw her head at any moment and his happiness would come to an end.

Naturally poets enjoy various skills and styles of reference to the same thing, especially if it is of a key significance in the poem. Here, in this poem Browning refers to his beloved in different occasions differently referring to her as my mistress, western cloud, and heaven.

In (line 35) there is another semantically deviant use of language, the poet compares his soul to a longcramped scroll. Again the absurdity arising from the comparison strikes the addressee because it is unusual to describe an intangible entity 'the soul' as a sheet of paper.

In (line 59) there is another manifestation of semantic deviation through the use of metaphor. Browning metaphorically deviates from the proper uses of language when he describes the body as the fleshly screen.

In (line 68) Browning resorts to metaphor, in this time the metaphor he uses is a very popular one, he compares implicitly rhythm with poetry. 
In line (107), Browning deviates from the logical expectation of language when he describes life as being forever old yet new. Here the interpretation that may arise is that the addresser wants the current moment, which he is enjoying with his beloved, to become everlasting, always the same, always unchanging, if there is a change it should be only in the intensity and fullness of their emotional experience. Otherwise, the same old life should continue; it should be old, but also new insofar as their emotional experience is concerned.

\section{Analysis of Pragmatic Deviation in Poem No. (1)}

In the first stanza (line 1-5) the addressee is projected into the middle of a conversation he does not know anything about. The poet does not provide any piece of information about the previous situation he was in, in these lines the poet breaks the maxim of quantity; more specifically the poet is not being sufficiently informative about what really happened to him or to his beloved. One might say for example that his beloved deserted him, she might have fallen in love with someone else. Another one might say that may be for some unknown reason fate prevented them from seeing each other. Another addressee might understand it in a different way; he might think that the addresser mistook the feelings and thought that they were in love and then and later discovered that there are no reciprocal feelings.

In (line 22) Browning pronounces one of the greatest lines he ever wrote. This line is rather problematic, since many assumptions may arise as one reads it, i.e., does the addresser want the world to end this night or is he afraid that the world may end tonight?.

In addition to violating the maxim of quantity by not being adequately informative, the addresser also, violates the maxim of manner. He violates the first two submaxims namely ambiguity and obscurity submaxims, i.e., he does not express himself clearly he leaves the addressee in the midst of obscurity and ambiguity as to what he really intends to convey.

In the third stanza (line 23) and (24) the poet suddenly describes a western cloud and compares it with his beloved. In this stanza Browning flouts the maxim of relevance, because the description of the cloud in the first four lines is not pertinent to the topic already in discussion. Thus, in order to arrive at the intended meaning the addressee needs to proceed in reading the poem.

In the sixth stanza (line 61-66) the poet, also, deviates pragmatically from the maxim of relation, when describes soldiers and their doings which does not correlate to the talk exchange in which he is engaged.

Similarly in the seventh stanza turns the talk immediately from the discussion of his love to the achievements of the poets and its futility. Here, the poet deviates pragmatically by violating the maxim of relation, i.e., he is providing pieces of information irrelevant to the talk.

In the eighth stanza, Browning makes another reference to more pragmatically irrelevant issue, namely, the discussion of the vainness of the works of the sculptors and musicians compared to his ride, which is irrelevant to the talk exchange.

\section{Analysis of Semantic Deviation in Poem No. (2)}

This poem demonstrates several instances which renders it difficult to correlate things together; this is partly due to the absurdity arising from the use of a special word in a different context from its ordinary one; and mostly due to the poet's display of his learning in this poem. The topic of the poem probably stimulates the poet to show his mastery of the language. He plays with the meanings of the words, creates new meanings, and adds them to the already existing ones.

Browning starts the semantic deviation by giving animate characteristics to inanimate entities. In lines(1-6) ,he gives the fields and the villages animate features when he describes them as 'sleeping' which is rationally impossible, thus giving rise to semantic absurdity that leads consequently to semantic deviation. Similarly, he describes the plain as having a bosom which is absurd. He is creating semantic deviation through personification.

In (line 5) Browning uses the word plain to refer to the uneducated and ignorant people. The plain is a metaphor for the 'simple-minded, uneducated and ignorant people'.

In (line 13) Browning describes the plain as being 'unlettered'. This gives rise to irrationality; it is absurd to describe a piece of land as being uneducated. The reference here is to the people living in this plain, that is to say it is a metonymic reference.

In (line 29) Browning gives the thorpes (villages) and crofts (fields) animate characteristics, the characteristics of sleep which is an animate characteristic. 
In (line 40) there is a wonderfully managed metaphor; Browning refers to his life as s 'dance'. He questions whether his 'dance' (life) finished, which is a popular theme in literature. Similar metaphors are used by men of letter, e.g., Shakespeare who compares life to a theatre stage where everyone performs his role.

In (line 63) there is another metaphor; Browning implicitly compares 'knowledge' to a feast, his intended meaning is to enjoy the whole 'feast' without feeling queasy or in discomfort, i.e., he wants to learn knowledge to its utmost.

There is another implicit comparison, metaphor, lines (69-72). Browning compares life to a building, he is expressing his own view of life, he indicates that he would rather plan his life before actually living it, just like someone who would plan how to construct a building before actually building it .Thus, Browning believes that before beginning to live and enjoy life, one should understand life, because such an understanding is necessary for real enjoyment.

In (line 95) there is another metaphor; Browning describes the need for learning as a sacred thirst. His soul felt a thirst to knowledge,he strived for knowledge as a hydropathic needs water for treatment.

In (line 125) Browning gives a human characteristic to a non-human entity; he describes death as having hands, i.e., he is personifying death and characterizing it with human characteristics, and this is semantically absurd and illogical.

In (lines 135-136) there is a periphrastic use of words highfliers, feathered race and swallows and curlews. The poet could have used only one of the alternatives to refer to birds. This may seem as a repetition or could be described as redundancy, but for the purpose of emphasis or probably for the purpose of using a flowery language, the poet choice is to use the three.

In (line 143) the irrational element is clearly observed. Browning uses the verb break with the noun joy; in ordinary language it may be absurd to say that joy is to be broken or could be broken, because the verb 'break' requires a tangible and concrete object to be used with it.

In the last line of the stanza, semantic absurdity is manifested obviously through the use of contradiction. He describes himself as living and dying which is semantically contradictory. The poet intends to say that the Grammarian was both in his life and death more sublime and lofty than the ignorant people thought him.

\section{Analysis of Pragmatic Deviation in Poem No. (2)}

In (lines 25-6) the addresser suddenly shifts from the praise of his master (the Grammarian) into his colleagues asking them to unify their tone, square their chest and raise their heads. This is irrelevant to the talk exchange in which the addresser is engaged. The poet deviates pragmatically when he gives information irrelevant to the topic.

Another aspect of the pragmatic deviation found in this poem is the indirectness of expression in (line 29), the poet refers to the sleep of the crop, thorpe and croft, here he is indirectly referring to the people living in these areas and not the land. Browning flouts one of the submaxims of the manner, namely the indirectness of expression submaxim. In (lines 35-6) there is another violation of the indirectness of expression submaxim, Browning indirectly compares youth to spring and old age to winter.

In (lines 69-72) the maxim of relevance is violated, the addresser is giving information irrelevant to the topic already in discussion, he starts speaking about building a house and the preparation for that. Meanwhile, he violates the sub-maxim of indirectness of expression, because here he is indirectly comparing life into a building rendering the whole expression obscure.

Through the poem, the addresser turns to the chorus, once he asks them to beware of the people looking at them and another time tells them that the way is narrow and they should walk two after two, sometimes he indicates where did they arrive to the gate of the town or to the market place; the exposition of these comments does not add to or change the direction of the discourse. All these comments are irrelevant to the discussion, so in these lines the poet deviates pragmatically by violating the maxim of relevance.

In the last line of the poem there is a violation of the maxim of quality; the poet gives information he cannot prove; living and dying are two extremely opposite situations that cannot be combined in one condition of some person. 


\section{Data Analysis via WS Tools}

Table 1. Frequency of occurrence of deviations in the selected data

\begin{tabular}{|l|l|l|}
\hline Type of Deviation & Frequencies of Occurrence & Total \\
\hline Semantic Deviation Poem No. 1 & $12 \%$ & \multirow{3}{*}{$47 \%$} \\
\hline Pragmatic Deviation Poem No. 1 & $8 \%$ & \\
\hline Semantic Deviation Poem No. 2 & $15 \%$ & \\
\hline Pragmatic Deviation Poem No. 2 & $12 \%$ & \\
\hline
\end{tabular}

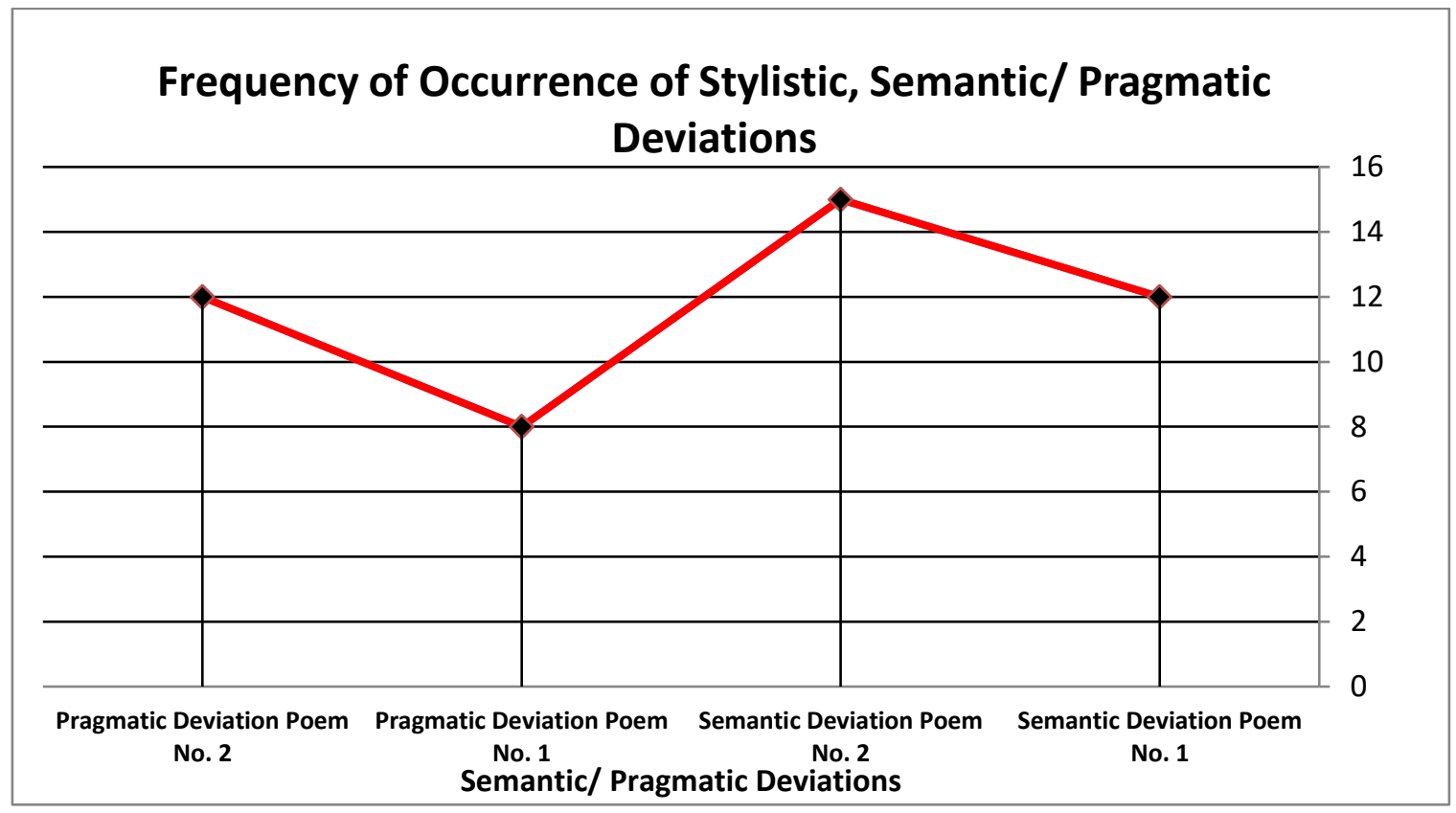

Figure 1. Frequency of occurrence of deviations in the selected data

Following the table and its visualized curve plotted in the figure above, it seems that Browning is aware of the norms of language, but he intentionally deviates from the norm to reveal his own idiosyncrasies. Browning, however, creates aesthetic devices in his poetry through deviation from the norms of language. The percentages show that Browning perfectly makes a balance in the process of deviation, especially 'semantic deviation For the $1^{\text {st }}$ poem' and 'pragmatic deviation of the $2^{\text {nd }}$ poem'. Both have shown exactly the same score (i.e., $12 \%$ ). This indicates that Browning skillfully employs the technique of stylistic deviation in his poetry to create obscurity, which adds a peculiarity to his poetry.

But, having a look on the other way around, the $2^{\text {nd }}$ poem scores the highest degree of semantic deviation (i.e., $15 \%$ ). Whereas, the $1^{\text {st }}$ poem scores a rather low degree of pragmatic deviation (i.e., $8 \%$ ). This might go hand in hand with the maxim of relation. It is probably the most difficult maxim to break. Although it can be argued that communication of some kind can still go on if any of the other maxims are broken, one cannot say that the cooperative principle is upheld at the points where the maxim of relation is broken. The other maxims can, in various degrees, be viewed in terms of the maxim of relation.

Furthermore, the breaking of any of the maxims of the cooperative principle does not mean that there is a total breakdown of communication, i.e., there might be a partial violation of one of the maxims or the cooperative principles. The breaking of a maxim may also involve some kind of 'trade-off', where one breaks a maxim in order to maintain another maxim. The latter of which may be more important in the communicative situation than the former.

\section{CONCLUSIONS}

Rounding off this study, it can conclude the following:

1. Deviation is an important stylistic device which men of letters resort to for aesthetic purposes. 
2. It is created by breaking the norms and the rules of the language. By the same token, it can be a nonbreaker of the rules when it is made as a result of the writer's choice and freedom to have a fuller advantage than usual in adopting and exploiting some elements in the text to give them eminence and liveliness by pushing them into a focus position or by calling attention to their irregularity and unexpectedness

3. Browning's style is perplexing and demanding, thus, requires analysis on different levels of language.

4. Deviation forms a yardstick by which Browning's poetry can be appreciated.

5. A writer can culminate his work through mastering the art of deviation to use language forcefully and effectively, if there are no aesthetic deviations in the literary work of a writer, the style might be ordinary. Stylistic deviation adds to aesthetic and communicative values, relevance and significance of a literary work.

\section{REFERENCES}

Bowles, H. (2010). Storytelling and Drama: Exploring Narrative Episodes in Plays. Amsterdam: John Benjamins Publishing Co.

Crystal, D. (1992). An Encyclopedic Dictionary of Language and Languages. Oxford, Blackwell Publishers. Crystal, D. (2004). A Dictionary of Linguistics and Phonetics. Oxford: Basil Blackwell.

Crystal, D. and Davy, D. (1969). Investigating English Style. London: Longman.

Cummins C.R. (2002). A Gricean account of linguistician meaning. Int. http://www.srcf.ucam.org/ camw3/Studies/.

Dijk, van T.A. (1977). Pragmatics and Poetics. University of Amsterdam: North Holland Publishing Company.

Easterby-Smith, M., Thorpe, R. \& Jackson, P. (2012). Management Research (4th ed.). London: Sage Publishing. Retrieved from https://books.google.iq/ (15 Dec. 2020).

Hartmann, R.. \& Stork, F (1981). Dictionary of Language and Linguistics. London: Applied Science Publishers.

Herman, D. (1995). Universal Grammar and Narrative Form. Durham \& London: Duke University Press.

Hussein, K. \& Al-Sahlani, A. (2019). Translation Assessment and Lexical Loss. A Corpus-Based Approach. Munich: GRIN Verlag.

Hussein, K. (2014). Issues in Literary Stylistics. Berlin: Grin Verlag.

Hutton, C. (2018). "Editors' Note to Chapter 3 Judges". In Durant, A. \& Leung, J. (eds.) 2018. Meaning and Power in the Language of Law. Cambridge: Cambridge University Press.

Jeffries, L. \& McIntyre, D. (2010). Stylistics. Cambridge: Cambridge University Press. Retrieved from www.bookfinder.com/ ( 9 Jan. 2021).

Jones, T. (2012). Poetic Language. Edinburgh: Edinburgh University Press.

Jurus, Jerzy (1994). The Elements of the Idiosyncratic: An Analysis of William Faulkner's Narrative Style. Int. jerzyjurus@interia.pl.

Leech, G. (1969). A Linguistic Guide to English Poetry. London: Longman.

Leech, G. and Short, M. (1981). Style in Fiction. London: Longman Group Ltd.

Munday, R. \& Chandler, D. (2020). A Dictionary of Media and Communication. Oxford: Oxford University Press.

Rabah, F.R. (1997). 'Linguistic Deviation in Literary Translation'. Unpublished Ph.D. Dissertation, Baghdad: Al- Mustansiriya University.

Scot, M. (2015). WordSmith Tools (ver. 5.0). Liverpool: Lexical Analysis Software.

Short,M. (1996). Exploring the Language of Poems, Plays and Prose. London: Addison Wesley Longman Limited.

Stankiewicz , E. (1960). 'Linguistics and the Study of poetic Language. In T. Sebeok (ed.). Style in Language. Cambridge, Mass: MIT Press.

Wardhaugh, R. (2010). An Introduction to Sociolinguistics. United Kingdom: John Wiley \& Sons Ltd.

Zhang, R. (2014). Sadness Expressions in English and Chinese: Corpus Linguistic Contrastive Semantic Analysis. London: Bloomsbury Academic Publishing Plc.

https://mypoeticside.com/poets/robert-browning-poems

https://www.gradesaver.com/robert-browning-poems/study-guide/summary-a-grammarians-funeral 